\title{
Ventrolateral Preoptic Nucleus (VLPO) Role in Turning the Ascending Arousal System Off During Sleep
}

\author{
Behzad Saberi* \\ Medical Research, Esfahan, Iran \\ *Corresponding author: Behzad Saberi, Medical Research, Esfahan, Iran
}

\begin{abstract}
Mini Review
Coordinated manner of action of the projections from monoaminergic cell groups, cholinergic and orexin neurons, produces arousal. Turning this arousal system off would result in producing sleep. There is an important role for the Ventrolateral Preoptic Nucleus (VLPO) to inhibit the arousal circuits during sleep. VLPO neurons are sleep active neurons [1-3]. Also, these neurons contain GABA and Galanin as inhibitory neurotransmitters. Such neurons receive afferents from monoaminergic systems. VLPO lesions would cause fragmented sleep and insomnia.
\end{abstract}

VLPO has two groups of neurons: One group located in the core of the VLPO and its neurons project to the tuberomammillary nucleus and the other group of neurons which is called extended VLPO, projects to the median and dorsal raphe nuclei and locus coeruleus, tuberomammillary nucleus and dorsal raphe as the arousal system components on one hand and VLPO on the other hand would be inhibitory in the mutual manner [4-6]. This results in a flip-flop electronic switch or circuit. This flip-flop design, prevents intermediate states to be occurred, facilitates switching between states of behavior and ensures behavioral states stability [7]. Such flip-flop design causes the monoaminergic system to be on the arousal side and the VLPO to be on the sleeping side.

\section{References}

1. Saper, Clifford B, Scammell, Thomas E Lu (2005) Hypothalamic regulation of sleep and circadian rhythms. Nature 437 (7063): 12571263.

2. Chou Thomas C, Scammell Thomas E, Gooley Joshua J, Gaus Stephanie, Saper Clifford B Lu (2003) "Critical Role of Dorsomedial Hypothalamic Nucleus in a Wide Range of Behavioral Circadian Rhythms". The Journal of Neuroscience 23 (33): 10691-10702.

3. Phillips AJK, Robinson PA (2007) A Quantitative Model of Sleep-Wake Dynamics Based on the Physiology of the Brainstem Ascending Arousal System. Journal of Biological Rhythms 22(2): 167-179.

4. Brown RE, McKenna JT (2015) Turning a Negative into a Positive: Ascending GABAergic Control of Cortical Activation and Arousal. Front. Neurol 6: pp.135.

5. Saper Clifford B, Fuller Patrick M, Pedersen Nigel P, Lu Jun, Scammell Thomas E (2010) Sleep State Switching. Neuron 68 (6): 1023-1042.

6. Gallopin Thierry, Fort Patrice, Eggermann Emmanuel, Cauli Bruno (2000) Identification of sleep-promoting neurons in vitro. Nature 404 (6781): 992-995.

7. Sherin J (1998) Innervation of Histaminergic Tuberomammillary Neurons by GABAergic and Galaninergic Neurons in the Ventrolateral Preoptic Nucleus of the Rat. The Journal of Neuroscience 18 (12): 47054721. 
This work is licensed under Creative Commons Attribution 4.0 License

To Submit Your Article Click Here: Submit Article

DOI: $10.32474 /$ PAPN.2020.02.000146

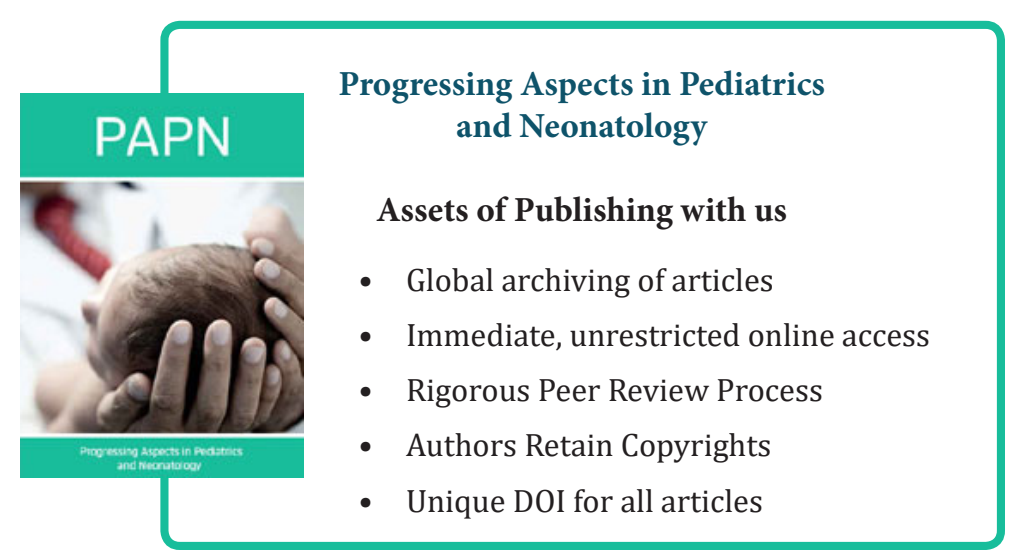

